\title{
Model of cross-cultural competence formation in future hotel business managers
}

\author{
K. Levadna \\ Kyiv University of Tourism, Economics and Law, Kyiv, Ukraine \\ Corresponding author E-mail: k.levadnaya@gmail.com
}

Paper received 23.11.18; Revised 26.11.18; Accepted for publication 27.11.18.

\begin{abstract}
https://doi.org/10.31174/SEND-HS2018-184VI30-13
\end{abstract}
\begin{abstract}
The paper reveals the model of cross-cultural competence formation in future hotel business managers under conditions of professional preparation. The main realization stages of the technology of cross-cultural competence formation in future hotel business managers under conditions of professional preparation have been characterized. The model structural constituents have been determined: components, principles, approaches, organizational and pedagogical conditions, criteria and levels of cross-cultural competence formation. The most efficient forms, methods and means of cross-cultural competence formation in future hotel business managers under conditions of professional preparation have been determined.
\end{abstract}

Keywords: model, cross-cultural competence, manager,hotel business, professional preparation.

With the entry of Ukraine into the European area, the hotel industry has been actively developing, attracting a large number of people with various cultural differences. Therefore, professional preparation necessitates internationalization of the views of the hotel industry specialists more often than not.

The structure of the most beneficial relations with representatives of the leading hotel world chains necessitates account for the differences in their cultures, mentality and national characteristics.

In this regard, the cross-cultural competence of the hotel business future managers acts as an instrument for adoption of effective organizational and managerial decisions in the hotel industry establishments. Their formation is aimed at the perspective development of the country's economy. This determines the relevance of cross-cultural competence of managers, the need for which is due to the emergence of social and cultural innovations.

Higher education of Ukrainian managers in the hospitality industry should train highly skilled professionals able to quickly adapt to their professional activities, effectively participate in international cooperation and adequately compete in the European labor market.

Therefore, it is necessary to strengthen the cross-cultural component in the educational process of professional training of future hotel business managers. In higher education institutions that train specialists for hotel business, the formation of cross-cultural competence in future hotel business managers within multicultural space becomes quite relevant. The cross-cultural competence formation in future hotel business managers contributes to improvement of the image and promotion of the hotel industry reputation.

Analysis of studies and publications has demonstrated significant contribution to the research of specialist professional preparation in the context of social transformations of such scientists as V. Andrushchenko, M. Ievtukh, I. Ziaziun, N. Nychkalo, V. Sydorenko, etc. Peculiarities of future spe- cialist personality development have been considered by $\mathrm{H}$. Ball, S. Sysoieva, V. Fedorchenko. N. Fomenko, etc., whereas the professional competence formation in future specialists have been investigated by L. Liubarets, A. Spitsyna, O. Shapran, etc. A number of scientists (L. Moroz, M. Skrypnyk, H. Tsekhmistrova, etc.) have studied the issues of managers training in Ukraine in the context of Bologna Agreement. The problems of culture formation in the professional activity of future managers have been tackled by A. Kazmerchuk and V. Liventsova.

Despite obvious significance of studies, the degree of elaborating the problem of cross-cultural competence formation in future hotel business managers remains insufficient. There is great demand for managers with formed professional culture in hotel industry as well as the necessity to improve the educational environment of their professional preparation. Therefore, the objective of the paper is the characteristics of cross-cultural competence formation in future hotel business managers in the process of their professional preparation.

Presentation of the main material. In the modern world, the activities of the hotel business manager are realized at the crossroads of cultures. Efficient cross-cultural management of the hotel business is created in partnership with representatives of other cultures and is based on recognition, respect for cross-cultural differences and formation of a common corporate value system that would be recognized and perceived by every business employee.

The term "cross-cultural" derives from the English word "cross", and means the interaction of different cultures and languages in a professional environment [1]. Nigel J. Holden considered culture as the most important resource in organization and as an object of cognitive management.

The basic principles of cross-cultural management, as formulated by Richard Gesteland in his book "Cross-cultural Behavior in Business" (Fig. 1) [3], may be taken as a basis for hotel business operations.

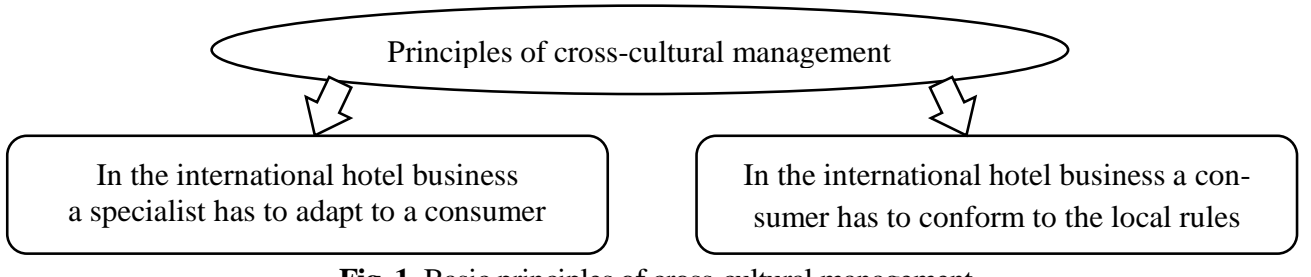

Fig. 1. Basic principles of cross-cultural management

Diversity and peculiarity of cultures are provided by competent HB managers. In higher education institutions, which train specialists for the hotel industry, the formation of student cross-cultural competence is growing more urgent, which is manifested in understanding of the specifics of cross-cultural relations that arise in the multicultural space 
when dealing with communicants that belong to more than two cultures.

The most characteristic areas of hotel business, where the intersection, interaction and collision of different cultures occur, are $\{4\}$ :

- hotel business management;

- interaction of professional subcultures in hotel business;

- managing corporate values;

- hotel business communication in the external environment;

- hotel business marketing;

- managing human resources;

- relocation, employment and career growth in other region, country;

- interaction of regions of Ukraine.

Cross-cultural competence formation in future managers of hotel business is necessary because the national hotel industry has many regional, locally territorial peculiarities. Regional cultural and country-specific realities are important for hotel business.

Knowledge of the peculiarities of national culture and culture in the business sphere of other ethnic groups, nationalities, peoples, civilizations becomes rather significant, as the more diverse the cultured sphere of hotel business, the more apparent cross-cultural differences, the higher communicative obstacles, the more critical requirements to the crosscultural competence of hotel business manager.

The following are the indices of cross-cultural competence of hotel business manager:

- awareness of manager's role in professional sphere of hotel business;

- continuous improvement of general and professional culture;

- increase of professional experience in managing business relations that arise in a multicultural environment: creation of tolerant interaction, successful communication, conditions of productive work and profitable business at the intersection of different business cultures;

- prevention and solution of intercultural conflicts within business environment.

Cross-cultural competence formation in future hotel business managers is associated with the improvement of the learning process itself focused on activating mental performance and forming professional skills of students.

An integral model is suggested to provide more efficient formation of cross-cultural competence in future managers in the process of professional preparation. Its structure consists of successive and interrelated elements and stages of the formation process during professional training at higher education institution (Fig. 2).

The target component of the model includes a social order, which is expressed in the need for professionals with formed professional culture in the hotel industry, thus the goal consists in the process of forming cross-cultural competence of future hotel business managers.

By specifying the purpose of the model, we have outlined a task: formation of educational-professional orientation and the leading motives of professional activity; provision of a set of knowledge, skills and abilities to achieve the quality and results of professional activity; formation of an individual style of future professional activity (Fig. 2).

Suggested model envisages realization of the main functions of the educational process of future hotel business managers (educational, motivational, developing, cognitive) and contains components (motivational, cognitive, pragma- tist, reflexive, emotional-volitional). Components are closely interconnected [2].

The basic principles (scientificity; systematicity and succession; conscience, activity and independence;thoroughness; connection of theory and practice in educational process of professional preparation; motivational learning and accounting for personality individuality) and approaches (system, pragmatist, personality development, competency-based) have been determined.

The model depicts organizational-pedagogical conditions for forming cross-cultural competence of future hotel business managers: development of the individuality of future hotel business manager on the basis of educational process socialization with account for peculiarities of future professional activity in hotel business; organization of educational process focused on success motivation in future professional activity; combination of methodical principles of crosscultural competence formation in future hotel business managers in the process of professional preparation and proper control of its formation.

The model of cross-cultural competence formation in future hotel business managers contains a technological component, which includes the technology of professional culture formation: stages, forms, methods, means, etc. Implementation of the model of cross-cultural competence of future hotel business managers in the context of efficient professional activity under real working conditions requires the use of appropriate teaching methods, namely: lecture, seminar, practical session, independent and laboratory work, individual study, scientific conferences, trainings, brain rings, quizzes, business games, integrated and binary classes, excursions, etc. [2].

The following criteria of cross-cultural competence formation in future hotel business managers may be outlined: value-motivational attitude of a student toward the activity in hotel business; cognitive; pragmatist; reflexive.

Within the frames of our study, the technology of crosscultural competence formation includes the following methods of control and correction (testing, questionnaire, selfcontrol, consultations, individual tasks, interviews). Implementation of the model envisages the presence of specific results in forming cross-cultural competence of future hotel business managers, moving to a higher level of cross-cultural competence of future professionals from elementary to creative one (Fig. 2). Preparation should result in formation of cross-cultural competence of future hotel business managers.

Formation of cross-cultural competence in future hotel business managers is considered as a process of mastering stable, integrated and system professional knowledge that envisages the ability to apply them in new, non-standard situations, developing personality traits and general ethicoprofessional culture, which will ensure their efficient professional activity.

Elaborated model of cross-cultural competence formation in future hotel business managers in the process of professional preparation (Fig.2) represents an efficient tool for designing professional training of skilled hotel industry manager in educational environment. This open model is constantly improved.

Therefore, the investigated model represents a complex system of interrelated elements. Stages of the study are aimed at the achievement of the goal of forming crosscultural competence in future hotel business managers in the process of professional preparation through person-centered and competence-based training. 


\section{OBJECTIVE: process of cross-cultural competence formation in future hotel business managers in the course of} professional preparation

Professional preparation tasks: formation of activity motives, professionally oriented personality traits, formation of individual style of future professional activity



Organizational-pedagogical conditions:

development of individuality of future hotel business manager on the basis of educational process socialization with account for peculiarities of future professional activity in hotel business; organization of educational process focused on success motivation in future professional activity; combination of methodical principles of cross-cultural competence formation in future hotel business managers in the process of professional preparation and proper control of its formation

\begin{tabular}{|c|c|c|}
\hline \multicolumn{3}{|c|}{ Methodical bases of cross-cultural competence of future hotel business managers } \\
\hline$\frac{1}{t}$ & 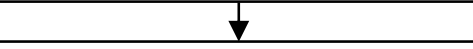 & 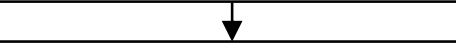 \\
\hline $\begin{array}{c}\text { Forms: } \\
\text { lecture, seminar, practical session, } \\
\text { independent and laboratory work, } \\
\text { individual study, scientific confer- } \\
\text { ences, trainings, brain rings, quiz- } \\
\text { zes, business games, integrated and } \\
\text { binary classes, excursions }\end{array}$ & $\begin{array}{l}\text { Methods: } \\
\text { verbal, visual, practical, problem, IT } \\
\text { usage, interactive methods, testing, } \\
\text { elaboration presentation, search for } \\
\text { information in Internet }\end{array}$ & $\begin{array}{l}\text { Means: } \\
\text { educational programs, recommen- } \\
\text { dations, reference notes of lectures, } \\
\text { visual aids, technical education } \\
\text { means, computer tools (programs, } \\
\text { tests), test cases, plans of seminars, } \\
\text { computer testing }\end{array}$ \\
\hline
\end{tabular}

\begin{tabular}{|c|c|}
\hline $\begin{array}{c}\text { Criteria and levels of cross-cultural competence formation in future hotel business managers } \\
\text { Calue-motivational, } \\
\text { cognitive; pragmatist; reflexive }\end{array}$ & $\begin{array}{c}\text { Levels: } \\
\text { elementary, reproductive, } \\
\text { sufficient, creative }\end{array}$ \\
\hline Result: formation of cross-cultural competence in future hotel business managers \\
\hline
\end{tabular}

Fig. 2. Model of cross-cultural competence formation in future hotel business managers in the process of professional preparation.

In our opinion, further formation of cross-cultural competencies in future hotel business managers requires studying the peculiarities of introducing modern innovational educa-

\section{REFERENCES}

1. Gordeyev RV Cross-cultural problems of international management [Electronic resource] / R.V. Gordeyev // Management in Russia and abroad. - №1. - 1998. - Access mode: http://www.cfin.ru/press/management/1998-1/01.shtml.

2. Liubarets V. V. Model and principles of formed professional competence of travel agents // V. V. Liubarets Herald of the tional technologies into the educational process, that take into account the direction of their professional preparation.
Taras Shevchenko National University of Lugansk № 15 (250), Fifth, III, 2012

3. Myasoedov S.P. Cross-cultural management [Electronic resource] / S.P. Myasoedov // Management staff. - №7 - 2006. - Access mode: http://www.top-personal.ru/issue.html?174.

4. Shutkova E.Yu. "On Cross-Cultural Management". M: Bardo. 2007. 